\title{
Evaluating amount of satisfaction for visit capabilities and infrastructures of Gorgan city in separation of touristic entrance regions
}

\author{
Ahmad Pour Ahmad ${ }^{1}$, Bahram imani ${ }^{2}$, Zeinab Valizadeh ${ }^{3,}{ }^{*}$, Zabihollah Torabi ${ }^{4}$, \\ Mansour rezaali ${ }^{5}$, Majid Rahmani Seryasat ${ }^{6}$, Mohammad Molaei Qelichi ${ }^{7}$, Neda \\ Shabani ${ }^{8}$, Sarah Azimzadeh ${ }^{9}$ \\ ${ }^{1}$ Professor, Faculty of Geography, University of Tehran, Tehran, Iran \\ 2 Assistant Professor of Geography and Rural Planning, University of Mohaghegh Ardabili, Iran \\ $3 *$ MSc Student of Geography and Environmental Hazards, Tehran University, Iran \\ $4 \mathrm{PhD}$ student in Geography and Rural Planning, Tehran University, Iran \\ ${ }^{5} \mathrm{PhD}$ student in Geography and urban Planning, Tarbiat Modares University, Iran \\ ${ }^{6}$ MSc Student of Geography and Tourism, Tehran University, Iran \\ ${ }^{7}$ PhD student in Geography and urban Planning, Tehran University, Iran \\ 8 Research Assistant at University of South Florida \\ ${ }^{9}$ Msc in Tourism, Department of Geography and Economic History, Umeå University, Sweden
}

\begin{abstract}
The general aim of this research is evaluating amount of satisfaction for visit capabilities and infrastructures of Gorgan city in separation of touristic entrance regions. This study is applicable and explanatory-analytical method is used for study. Used statistical community is consisting entered tourists from seven touristic regions to Gorgan. In this study, probabilistic multistage cluster sampling method was used. So after calculation of sample numbers by using Kokeran's formula, some regions were selected as research sample from all of touristic absorptions and questionnaires randomly were distributed among them and then were gathered. Anova test, Danken test and the mean of visitor's opinions were employed for analysis of data. Also the graphical output of data was depicted through Arc Map software. The findings of research showed that Gorgan tourists have announced unsatisfaction of themselves about capabilities and touristic infrastructures of this city. Nevertheless among different regions there is a meaningful disagreeability. Finally with consideration to operated evaluations about satisfactory condition of tourists related to capabilities and infrastructures of the city for improving situation, suitable solutions have been offered.
\end{abstract}

Keywords: Tourism, satisfaction, facilities and infrastructure, Gorgan 


\section{Introduction}

Tourism is the largest and most diverse industry in the world. Many countries know this dynamic industry as the main source of income, employment, infrastructure development and private sector development. Throughout the world, particularly in developing countries, means that where other forms of economic development such as manufacturing or mining is not economically or have not very important role in the business, there is a great attention to tourism development. Today, the economic and employment aspect of tourism is too much that it can be regarded as the driving force of the economy of any country (Brown, 2003). Along with becoming more competitive tourism market, perceptual value of tourist as one of the most influential factors on tourist satisfaction and subsequently his loyalty to a particular promenade become very important (Alavi, et al, 1392:1). To achieve this task, every country, city or region in addition to produce tourism infrastructure and product and service offerings, should be able to express the benefits of travel to the area and cause good image of his country, city or region in the minds of tourists. In order to tourism practitioners be able to do it well, they should use appropriate ways for tourism (Ziayi, 64: 1388). Regarding the role of satisfaction of tourists in tourism development, it should be noted that the type of attitude on tourism depends on tourist satisfaction. Tourist satisfaction is a function of the fulfilling the needs of tourists in the host community. The host must meet the security needs of the tourists. So the social environment of the host society must be prepared to accept a tourist. Accordingly satisfaction of tourists is one of the most competitive factor and best indicator for ensuring growth and future earnings and tourist satisfaction as an important criterion for assessing the quality of work will be considered. If the level of tourist satisfaction and providing the expectations of tourists be more, the extent of attracting tourists and tourism development is more (Hezar Jaribi and Najafi, 1391: 123-124). Gorgan, is one of the Touristic towns of Iran that appropriate utilization of tourism potential depends on the knowledge, accurate assessment of tourism facilities and infrastructure; so to prevent and reduce the negative impact of this approach on the performance, spatial distribution and organization of tourism facilities and infrastructure, proper planning should be done to reduce the shortcomings in this section. Obviously, the proper operation of the capacity of tourism requires study and careful planning based on tourist opinions. With regard to the issues raised in this article, it is tried the performance of various sectors of the tourism authorities and amount of development of tourism facilities and infrastructure in terms of intellectual in Gorgan (quality of service) be assessed.

\section{Research Literature Tourism}

The tourism industry is a combination of several activities in the chain in order to serve the tourists. So, tourism includes all phenomena and relationships arising from the interaction between tourists, tourism product suppliers and vendors, governments and host communities in the process of absorption and reception of tourists (Mcintosh, 1995: 9). Tourism and leisure activities in a new way, is an outcome phenomenon and at the same time is an integral part of the industrial society and the main loop in its reproduction (Momeni, 1386: 15). Although there is no agreement on a single definition of tourism, but a general definition for it is described as a leisure activity for a person or group of people (Narayan, 2002: 15). Jonathan Yuri (1990) asserts that the purpose of tourism is watching carefully to see the different perspectives, landscapes, cities, or a way of life (culture) (Jepson, 2004: 48). Another expert in a simple definition, knows tourism as whatever related to tourists and related services for them (Fennell, 2000: 4). In general, tourism said to tourist activities and actions that are related to tourist, and all the activities that tourists do when traveling to a place outside of their residences. So, main character of tourism is in the 
first place, that is a trip away from home or work, and second, that sometimes non-stop nocturnal in short-term stay (Sharif Shahidi et al., 1388: 101).

\section{Urban Tourism}

One of the main purposes that affect tourism trends in the world in the past decade is urban centers. Growth of short trips converts these places to one of the main tourist centers, and this phenomenon has been occurred further in reduction of tourist trips around the world (Saifuddini et al., 68: 1389). Cities are attractive for all ages. People want to spend their holiday in the city. Characteristic of cities differ "urban tourists" from other tourist groups (Low, 1996: 168). Also, it has an important role in cities all over the world. Urban Tourism is a complex combination of different activities that occurs by incorporate specific environments and enables the city to attract visitors. Understanding the basic elements of tourism helps us to understand urban tourism. Urban tourism, include new urban phenomenon that underlies a range of social behaviors according to the characteristics of the city. Behavioral patterns of tourists in the city are defined as a function of the attraction patterns, as municipal services and social relations. (Movahhed, 1386: 42). Considering the mentioned elements, urban tourism can be defined as "urban tourism is travel to the city with various incentives and facilities based on various attractions and facilities in the city, and it will create the charm" (Movahhed, 1381: 65). Tourists who come to the city have different incentives and reasons such as visiting friends and relatives, visiting museums, going to the theater and cinema, considering sport events, see the sights of city, finding entertainment such as exhibition, stores and so on. Considering issues that mentioned above, we can define a urban tourist as "urban tourists is a person who travel to a city or town apart from their normal place of residence for motivation and fun, business, visit friends and relatives, exploitation and use of space, facilities and attractions in the city or doing other activities.

This travel not get along less than 24 hours, or more than a year (Movahhed, 1381: 66). Especially tourism, sustainable tourism management in many countries is important as a symbol of cultural identity, natural, human and economic sectors. Therefore, the sustainability of tourism requires systematic attention to the technical, cultural, political, economic, environmental, and historical aspects and tourist attractions towards the preservation and sustainability of the resources according to the needs of today and for the future (Movlayi Hashtchin and Khoshnoud, 11: 1386).

\section{Satisfaction of Tourists}

Dictionary says satisfaction is (Satisfy or pleasure and Resolve needs). Create a state of happiness, satisfaction and compliance as a result of supply and demand, and meet the needs of clients that occur by the service provider, called satisfaction. According to (Cutler), the level of satisfaction is a function of the difference between perception and expectations of the person (Worth et al., 1389). Another group considers satisfaction as evaluation of the quality of the services or received goods. Among some other, meeting the demands and expectations shed satisfaction. According to mentioned above, it can be said satisfaction is the process of comparing the expected performance and actual performance that may occur, or the perception that occurs depending on the perception of citizens (Hashemi and Hajipour 1390; 129).

The satisfaction is a difference between performance and expectations. If the function is equal to or higher than expected, if the customer is satisfiedand if expectations are more than performance, the customer is unsatisfied. This suggests that the absolute performance of the product or service is not directly impact on satisfaction. In assessing satisfaction with public services, the actual level of performance compared with their expectations (Deichmann and lall, 2007: 652). In fact, satisfaction is obtained when people meet a result of fulfillment of the expectations (Munusamy and Fong, 2008: 69). Companies' attitude on order to development of a competitive environment, forced to attract more sales and earn more profit focused on customer satisfaction. The transition from a traditional economy and intense competition in all aspects of modern world, convert customer to a central element of all activities of the organization; so that in competitive perspective, survival and continuity 
of organizations depends on identifying and attracting new customers and retain existing customers $\left({ }^{* * *}\right)$. With reference to the tourism industry, it can be concluded that the most likely places that tourists like to travel there have recommended to others, usually a stable group of people came to the touristic destination (Ranjbaran, 1386: 66) which is one of the most effective type of marketing and development (Soderlund, 1998). furthermore, the tourist satisfaction increase the survival rate of support, loyalty and attracting tourists, it also helps in achieving economic goals, such as increasing numbers of tourists and the interest rate. Finally, there is a positive correlation between satisfaction and long-term success in tourist destination (Saeedi et al, 11 389: 5).

\section{Presentation of case study}

Gorgan city is located at the western part of the Golestan province, at an altitude of 155 meters above the sea surface. This city is located at the range of latitude and longitude $\left(54^{\circ}, 24^{\prime}\right.$ east longitude and $36^{\circ} 49^{\prime}$ north latitude) on the northern slopes of the Alborz mountain range. Southern part of the city is overlooking the forested highlands. According to the 1390 Census of Population and Housing, Gorgan has 350,000 residents (Census of Population and Housing, 1390). Major tourist attractions of Gorgan are NaharKhoran Forest Park, Alngdarreh, the land of Hezar Pich, old town, Naal Bandan market, Jamee mosque,Ghalee Khandan hill.

\section{Map (1) Political Subdivisions (Drawing: the authors)}

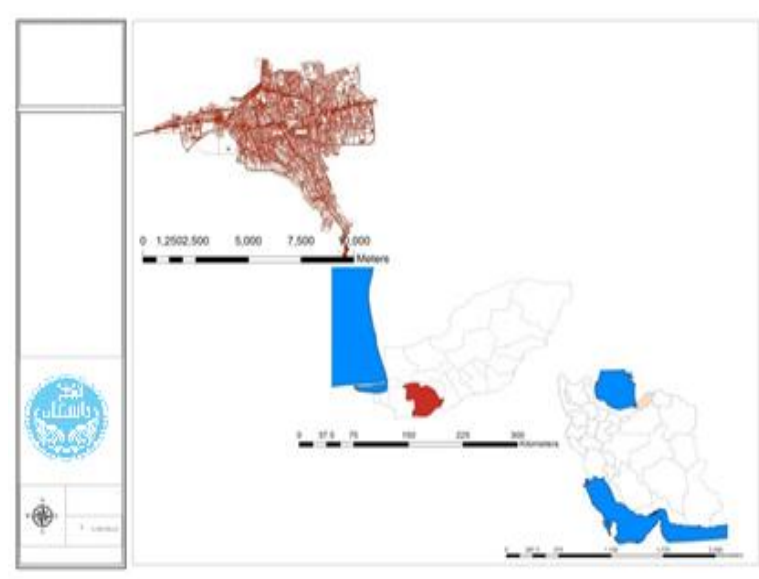

Processing: The authors

\section{Research Method}

Research Method is a combination of descriptive analytical methods and its approach practical. In this research the aim is assessment the opinion of incoming tourists to this city from seven touristic regions, in relation to the urban facilities for development of tourism market. In the objective perspective, the quality of tourism services can be done by the relevant authorities, based on the criteria and standards set, but the mental aspect (of the study), a feeling of satisfaction about utilization of urban tourism determines the quality of the service providers. In fact, by using this method the relation between the efficiency, space tourism and attracting tourists can be found. In this study, model (1) is used to evaluate the level of tourism development. This model can identify weaknesses and disadvantages of tourism infrastructure and facilities and efforts in order to resolve these problems in the development of the tourism market. It also increases the tourist attraction in studied city.

Figure 1: The development of the tourism market trend (source: authors)

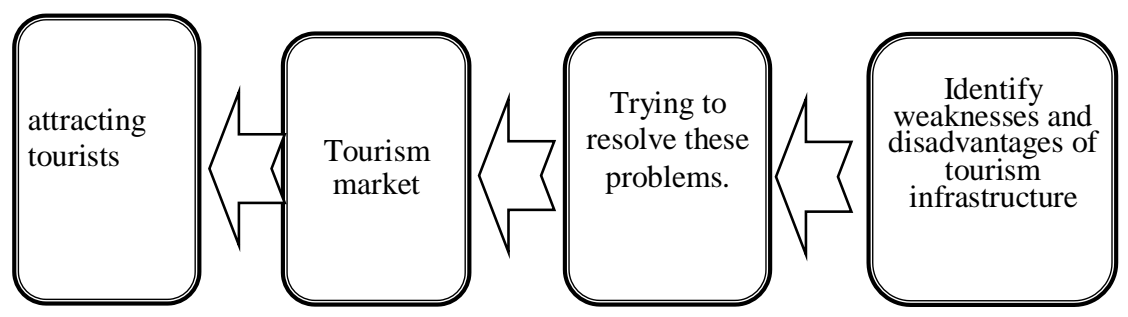

\section{Validity and reliability of guest's population:}

In order to assess the validity of the questionnaire, we have tried to make use of items that in previous research has been studied and evaluated by researchers and experienced professors. To ensure more after compiling the questionnaire, the teachers and advisors and 
experts' opinion was used for validation. In addition, in this study, Cronbach's alpha was calculated (0.81), it shows the characteristics of the building and had high internal consistency.

\section{Sampling method for questionnaire of Guests population:}

In this study, full data collected from the touristic areas of Gorgan was impossible because of time limitation and financial problems, so multistage cluster sampling method was used. The sample size was calculated using the Cochran formula (400 residents), the whole touristic area was (the Old City, Naharkhoran Forest Park, pilgrimage centers, shopping...). Some regions were selected as sample of study and questionnaires were distributed and collected among them randomly.

\section{Data Analysis Findings of the study:}

\section{1-5- tourism markets of Gorgan:}

Cultural Heritage and Tourism Organization, has divided the country into seven large touristic regions (Map 2). In this research, is tried to perform descriptive and inferential analysis, based on the population from these seven guest area. Data from the questionnaire show that Alborz contains $34 \%$ of the market share of tourism in Gorgan, and Religious area (21.5\%), sabalan (16\%), Zagros (12.5\%), the heart of Iran $(7.5 \%)$, the South Karavan Ro $(5 \%)$, ancient $(3.5 \%)$, have acquired next order in rank.

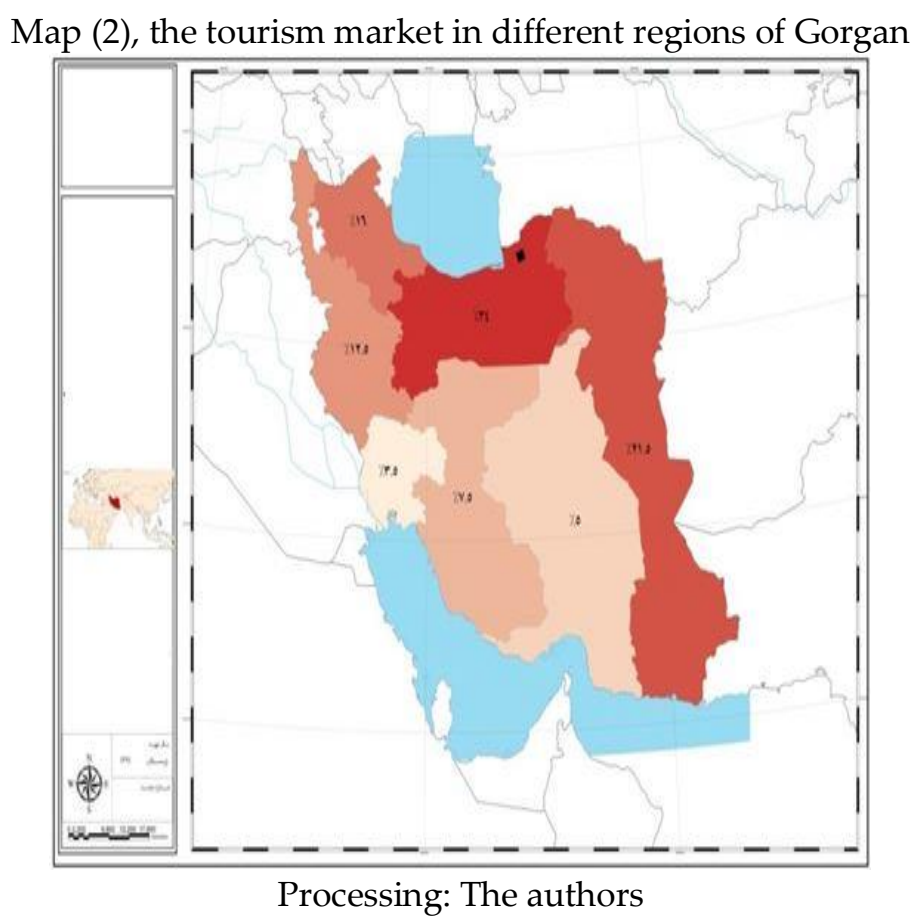

\section{5-2- General characteristics of respondents:}

In descriptive statistics, frequency distribution of respondents will see according to different variables such as sex, marital status, education, occupation, etc., tourists. Thus, from information extracted from the questionnaire, the statistical sample is 400 residents, 260 or $65 \%$ of the respondents were male and 35 percent or 140of them are women. 337 or $84.3 \%$ were married and $15.8 \%$ of them were single. $\ldots \%$ of the respondents were illiterate, $33 \%$ were educated in $6^{\prime}$ th of elementary or diploma, $57 \%$ had
Associate Degree or Bachelor's Degree, 10\% respondents have a degree and a master's degree and 10\% have Master's degree or higher. ,. 35 percent of respondents are public sector employees, $20 \%$ of them are private sector employees, 41 percent are self-employed, unemployed are $4 \%$ and $3 \%$ of respondents' incomes is less than 250000 Toman per month, $36 \%$ between 250000 to 500000 Toman, 46 percent between 500000 to 1 million Toman, 7\% between 1 and 2 million and $8 \%$ of them more than 2 million Toman. 2 percent of respondents' expense is lower than 250000 Toman, $21 \%$ 
between 250000 to 500000 , 34\% between 500000 to 1 million, $24 \%$ between 1 to 2 million and $19 \%$ of them more than 2millions. $45.1 \%$ of respondents travel alone, $14.6 \%$ travel with their family and $25.5 \%$ with the group.

\section{3-5-evaluation average satisfaction of tourists and tourism infrastructure facilities of Gorgan:}

Comments obtained from assessments indicated the components of the private sector with an average service speed of 2.59 , and the average quality of information and awareness program of 2.5, quality entertainment at average of 2.34 are evaluated under the average range. But relatively, respondent's highest level of satisfaction about the city's tourist facilities, owned by these components has been evaluated, and in the other hand public transport by an average of/1.89, amount of investigation into the situation of the city Sightseeing with an average amount of 1.94 were evaluated below the average and poorly, according to the respondents, have won the lowest rank in terms of satisfaction. Table 1 shows the average Satisfaction of tourism facilities of Gorgan in different regions.

Table (1), assessing the satisfaction of tourist about tourism facilities and infrastructure in Gorgan

\begin{tabular}{|c|c|c|c|c|c|c|c|c|}
\hline tourism facilities and infrastructure & 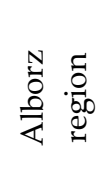 & 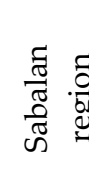 & 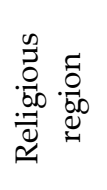 & 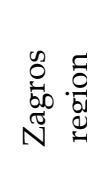 & 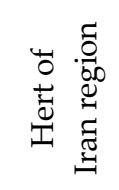 & 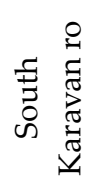 & 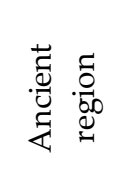 & 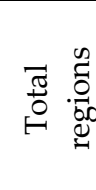 \\
\hline Road traffic situation & 2 & $2 / 28$ & $2 / 01$ & $2 / 34$ & $2 / 37$ & $2 / 80$ & $2 / 14$ & $2 / 165$ \\
\hline traffic situation in the city & $1 / 8$ & $2 / 53$ & $1 / 86$ & $2 / 42$ & $2 / 50$ & $2 / 40$ & $2 / 28$ & $2 / 11$ \\
\hline Reception centers outside the city & $1 / 97$ & $2 / 45$ & $2 / 08$ & $2 / 34$ & $2 / 50$ & $2 / 90$ & $2 / 50$ & $2 / 22$ \\
\hline The catering centers in the city & $1 / 822$ & $2 / 28$ & $1 / 87$ & $2 / 24$ & $2 / 25$ & $2 / 50$ & $2 / 57$ & $2 / 04$ \\
\hline Quality of residential centers & $1 / 866$ & $2 / 45$ & $2 / 43$ & $2 / 16$ & $2 / 25$ & $2 / 40$ & $2 / 57$ & $2 / 182$ \\
\hline Quality of food and drinks & $1 / 859$ & $2 / 29$ & $2 / 22$ & $1 / 91$ & $2 / 50$ & 3 & $2 / 35$ & $2 / 122$ \\
\hline Police and law enforcement cooperation & $1 / 814$ & $2 / 48$ & $1 / 62$ & $2 / 38$ & 3.28 & $2 / 80$ & $3 / 28$ & $2 / 125$ \\
\hline Security & $2 / 303$ & $2 / 45$ & $2 / 08$ & $2 / 59$ & 3.12 & $2 / 70$ & 3 & $2 / 39$ \\
\hline Public Health & $2 / 570$ & $2 / 48$ & $1 / 52$ & $1 / 97$ & $2 / 53$ & $2 / 30$ & $2 / 42$ & $2 / 235$ \\
\hline Car situation elimination of defects service & $1 / 859$ & $2 / 50$ & $2 / 63$ & $2 / 59$ & $2 / 75$ & $3 / 50$ & $2 / 35$ & $2 / 382$ \\
\hline Capacity and the availability of parking & $1 / 918$ & $2 / 34$ & 1 & $1 / 59$ & 2 & 2 & $2 / 14$ & $1 / 76$ \\
\hline public transport & $1 / 807$ & $2 / 39$ & $1 / 31$ & $2 / 20$ & $2 / 12$ & $2 / 20$ & $2 / 42$ & $1 / 897$ \\
\hline Situation of signs in Sightseeing & $1 / 874$ & $2 / 35$ & $2 / 04$ & $2 / 30$ & $2 / 25$ & $2 / 40$ & $3 / 14$ & $2 / 110$ \\
\hline Quality of of information and awareness & $2 / 851$ & $2 / 45$ & $2 / 46$ & $1 / 97$ & $2 / 50$ & $3 / 10$ & $2 / 78$ & $2 / 56$ \\
\hline Dealing approach of Gorgan residents with tourists & $1 / 718$ & $2 / 60$ & $1 / 34$ & $2 / 30$ & $2 / 46$ & $2 / 40$ & $2 / 92$ & $1 / 950$ \\
\hline Situation of price in compared with origin region & $1 / 807$ & $2 / 39$ & $1 / 97$ & $2 / 61$ & $2 / 50$ & $3 / 30$ & $2 / 57$ & 2/182 \\
\hline Amount of to handle the situation of Sightseeing & $1 / 807$ & $2 / 53$ & $1 / 55$ & $1 / 79$ & $2 / 25$ & $3 / 10$ & $2 / 64$ & $1 / 945$ \\
\hline The rate of private sector service & $1 / 807$ & $3 / 01$ & $3 / 37$ & $2 / 51$ & 2/84 & $2 / 40$ & $3 / 14$ & 2/592 \\
\hline Rate of public sector service & $1 / 925$ & $2 / 57$ & $2 / 15$ & $2 / 20$ & $2 / 50$ & $3 / 30$ & $2 / 71$ & $2 / 245$ \\
\hline Quality of entertainment programs & $1 / 874$ & $3 / 01$ & $2 / 32$ & $2 / 12$ & $2 / 93$ & $3 / 15$ & $3 / 14$ & $2 / 345$ \\
\hline
\end{tabular}

Satisfaction of seven areas about tourism facilities and infrastructure in Gorgan is visible Table (2) and the map (3). The results of this evaluation indicate that the area of south Caravan Ro with average of 2.71 has the highest satisfaction tourism facilities and infrastructure in Gorgan and the Heart of Iran region with 2.52, Sabalan region with 2.49 , Zagros region with 2.23, ancient region 2.20, religious region with 1.99 and Alborz region with 1.96 are in the next rank.

Table (2), assessment of satisfaction of tourism facilities and infrastructure in Gorgan

\begin{tabular}{|c|c|c|c|c|c|c|c|}
\hline regions & $\begin{array}{c}\text { Alborz } \\
\text { region }\end{array}$ & $\begin{array}{c}\text { Religious } \\
\text { region }\end{array}$ & $\begin{array}{c}\text { Ancient } \\
\text { region }\end{array}$ & $\begin{array}{c}\text { Zagros } \\
\text { region }\end{array}$ & $\begin{array}{c}\text { Sabalan } \\
\text { region }\end{array}$ & $\begin{array}{c}\text { Hert of Iran } \\
\text { region }\end{array}$ & $\begin{array}{c}\text { South } \\
\text { Karavan ro }\end{array}$ \\
\hline average & 1.96 & 1.99 & 2.2 & 2.23 & 2.49 & 2.52 & 2.71 \\
\hline
\end{tabular}


Map (3) zoning satisfaction of tourism facilities and infrastructure in Gorgan

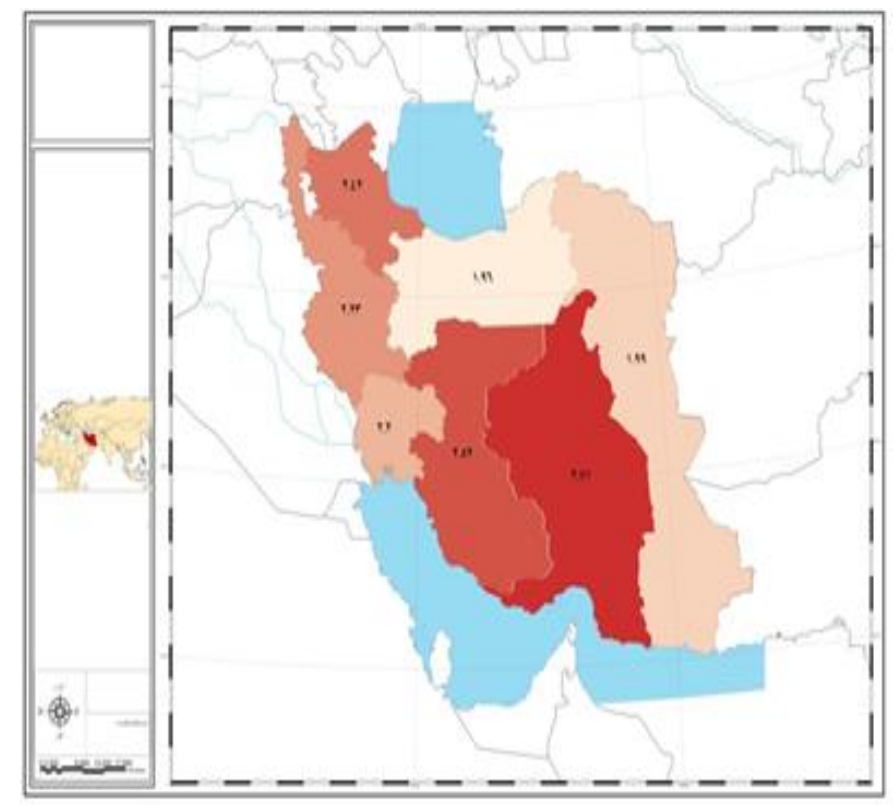

Survey of a meaningful amount of satisfaction of respondents in seven selected regions

for tourism facilities and infrastructure in Gorgan through a one-way ANOVA.

To assess meaningful differences in the attitudes of the regions one-way ANOVA method was used. Descriptive evaluation in a way, sig is standard and if be higher than (0.05) there is not a significant difference between the regions, but if the amount is less than (0.05), there a significant difference between the regions in response to questions.
According to one-ay ANOVA assessment of 7 regions (Table 3) in relation to the satisfaction of tourism facilities and infrastructure in Gorgan, there is statistically significant difference between the 7 regions. This reflects our assessment is meaningful. This means that people questioned in seven areas to assess the satisfaction of tourism facilities and the infrastructures are controversial. This Disagreement leads to significant differences between the regions level.

Table (3): survey of a meaningful amount of satisfaction of respondents in seven selected regions for tourism facilities and infrastructure in Gorgan through a one-way ANOVA:

\begin{tabular}{|l|l|l|l|l|l|}
\hline & Sum of Squares & df & Mean Square & F & Sig. \\
\hline Between regions & 25.203 & 6 & 4.201 & 57.708 & .000 \\
\hline Within Groups & 28.606 & 393 & .073 & & \\
\hline Total & 53.810 & 399 & & & \\
\hline
\end{tabular}

Survey of meaningful level of satisfaction of respondent in seven regions about tourism facilities and infrastructure in Gorgan by Duncan test:

Duncan test was used to analyze and determine meaningful differences in evaluation of factors. The results of the Scheffe test divide the effects of different regions or groups in a meaningful position into homogeneous and non-meaningful group. In other word, this test shows to the satisfaction in which areas do not have a meaningful difference. As indicated in table (4), in seven studied regions Alborz area has the most meaningful relation with "south Karavan Ro" area. This implies that people who was put into question in this area is not in line with comments. So that the "South Karavan Ro" is in highest level of satisfaction of tourist facilities and infrastructure assessment in Gorgan and 
Alborz region is in the lowest level. "Sabalan" People in the two regions had similar comments. area, the "Heart of Iran" and the South "Karavan Ro" have not meaningful relationships, means:

Table (4), evaluating satisfaction of tourism about facilities and infrastructure in Gorgan by using Duncan test

\begin{tabular}{|l|l|l|l|l|l|}
\hline \multicolumn{2}{|l|}{ regions } & \multirow{2}{*}{ frequency } & \multicolumn{4}{l|}{ Subset for alpha =0.05 } \\
\cline { 3 - 7 } & & 1 & 2 & 3 & 4 \\
\hline Alborz Region & 135 & 1.9630 & & & \\
\hline Religious region & 86 & 1.9953 & 1.9953 & & \\
\hline Ancient region & 14 & & 2.2036 & 2.2036 & \\
\hline Zagros region & 49 & & & 2.2316 & \\
\hline Sabalan region & 64 & & & & $2 / 4953$ \\
\hline Hert of Iran Region & 32 & & & & $2 / 5219$ \\
\hline South Karavan Ro Rejion & 20 & & & & $2 / 7125$ \\
\hline Sig. & & 1.000 & .126 & 1.000 & .094 \\
\hline
\end{tabular}

\section{Conclusion}

The evaluations in this study showed, incoming tourists to the Gorgan are not satisfied for city tourism facilities and infrastructure. Therefore, that their satisfaction about Gorgan is poor and Gorgan have no mental development, in tourists' opinion. This situation reflects the low quality of tourism services to tourists. According to the above description, it is necessary to evaluate development of tourism marketing potential capabilities of Gorgan. It means passengers, who traveled from other provinces or regions to Gorgan and recognized the strengths of this touristic region, can be used to strengthen these areas. For provinces and territories which have the lowest passenger and satisfaction about tourist attraction of Gorgan, it is tried to overcome weaknesses and the variety and quality of service and advertising increase. This will result in addition to strengthening and further use of the areas that have the greatest potential to attract tourists, increasing potential capacity of other region in attracting tourists and development of tourism in province will happen. This optimized situation requires the creation of an integrated management, and program coordinator to they be able in addition to removing the shortcomings and obstacles to attracting tourists, higher quality of existing facilities and infrastructure to tourists. Observing these factors ultimately, leads to efficient management of tourism and moving toward the development of city.

\section{References}

Ranjbaran, Bahram (1386), Assessment of repeating trip to Isfahan on satisfaction of foreign tourists, Journal of Geography and Development No. 9. Population and Housing Census 1390

Saeidi Ardakani, Saeid, Mir Ghafouri, Seyd Habib Allah and Barghi, Shahin (1389), Identify and prioritize the factors affecting the level of satisfaction of foreign tourists in Shiraz by using techniques of factor analysis and multi-criteria decision making, Quarterly Journal of Tourism Studies, No. 13,1-23.

Seifoddini, F., Shaabani Fard, M., Hosseini, A., Rashidi, M., (1389), Quality and capacity of urban tourism based on Behavioral pattern of tourism and host community, Case Study: City of Isfahan, Human Geography Research, No. 71

Shayan, H., Taghiloo, A. A., Khosrobeigi, R., (1389), Assess the satisfaction of villagers from residence environment: A case study Komijan city, Quarterly Journal of village and Development, No. 4.

Sharif Shahidi, M., Ardestani, Z., Goudarzi, S., Mohammad, M., (1388), Evolution of tourism 
Effects in planning of rural areas, Research in human geography, No. 67.

Alavi, S. M., Najafi Siahroudi, M., Mirzayi, Z., Study of factors influencing tourist satisfaction through their conceptual value of the walkway, Fifth Conference on Urban Planning and Management

Movahhed, A., (1381) Study and analyze the spatial pattern of urban tourism, Case Study: Isfahan, PhD thesis, University of Modarres

Movahhed, A., (1386), Urban tourism, Ahvaz, Shahid Chamran University Press.

Hashemi, S. M., YahyaPour, M., (1390), Principles of management of municipal utilities, Publication of municipalities of country. 4

Hezar Jaribi, J., Najafi, M. M., (1391), Sociological study of factors affecting the development of tourism in Iran (with the approach of attracting foreign tourists), Journal of Geography and Environmental Planning, No. 3

Ziayi, M., (1388), Typology of tourists in second homes and Physical Impact on Rural Areas, Journal of Geographical study, No. 4

Brown D. (2003), Rural Tourism: An Annotated Bibliography, Regional Economist, Washington.

Deichmann, uwe. lall. v.somik (2007): citizen feedback and delivery of urban services, world development,vol.35,No.4,PP.649-662

Fennell D. "Ecotourism an introduction" Routledge, London and New York (2000).

Jepson M. E., "The Impact of Tourism on a natral resource Community: Cultural rasistance in corte Florida", University of Florida (2002).

Low Ch., "Urban tourism: selected case studies, uaban tourism project working paper no 1 , department of geography, university of salford

Munusamy, J. and Fong, V.O(2008): An Examination of the Relationship between Service Quality and Customer Satisfaction in a Training Organization, Unitar E-Journal Vol. 4, No. 2.
Nrayan D., "Impacts of Tourism on Economic and Demographic development in a rural Spanish pueblo", University of Central Oklahoma (2002).

Söderlund, M. (1998). "Customer Satisfaction and Its Consequences on Customer Behavior Revisited. The Impact of Different Levels of Satisfaction on Word-of-Mouth, Feedback to the Supplier and Loyalty." International Journal of Service Industry Management, 9 (2): 169-88. 